\title{
Predictive geolocation: forensic soil analysis for provenance determination
}

\author{
${ }^{1}$ Helford Geoscience LLP, Trelowarren Mill Barn, Mawgan, Helston, Cornwall, TR12 6AE, UK; *Corresponding author, \\ E-mail:dpirrie@helfordgeoscience.co.uk \\ ${ }^{2}$ School of Applied Sciences, Faculty of Computing, Engineering and Sciences, University of South Wales, Glyntaf, Pontypridd, Rhondda \\ Cynon Taff, CF37 4AT, UK; International Union of Geological Sciences, Initiative on Forensic Geology (IUGS-IFG) Special Publications Adviser \\ ${ }^{3}$ The James Hutton Institute, Craigiebuckler, Aberdeen, AB15 8QH, Scotland, UK; Treasurer, International Union of Geological Sciences, \\ Initiative on Forensic Geology (IUGS-IFG) \\ ${ }^{4}$ AWE Plc, Aldermaston, Reading, RG7 4PR, UK
}

(Received: December 1, 2016; Revised accepted: March 4, 2017)

http://dx.doi.org/10.18814/epiiugs/2017/v40i2/017016

Soil forensics is most commonly used to test an association between soils at a known location with soils recovered from exhibits recovered from a suspect. This type of comparative analysis is now a routine technique in many laboratories world-wide. Soils are however, very complex materials made up of natural inorganic, organic and manmade components. The distribution and abundance of these components is generally controlled by a range of predictable factors, such as bedrock geology, surface processes, plant and animal biogeographical distributions and anthropogenic processes. As such, the composition of a soil can be used as a predictive tool to describe the nature of the location where that soil originated. This approach to soil forensics, termed predictive geolocation, has many applications in criminal, environmental and intelligence based investigations.

\section{Introduction}

The traditional application of soil forensics is in the examination of samples recovered from exhibits relating to an enquiry and the comparison of their attributes with soil samples collected from known locations where an offence is thought to have occurred. Thus for example, soil from an item of footwear might be compared with the soils present within a clandestine grave or at a surface body deposition site (e.g., Bull et al., 2006; Ritz et al., 2009). In general, this type of comparative analysis is relatively simple, and can be achieved by focussing the soil analysis on either the organic components present (e.g., pollen, wax markers, plant DNA, micro-invertebrates) or the inorganic components (e.g., rock fragments, mineral grains, man-made particulates) or ideally both aspects in conjunction. In comparative analysis the critical questions, particularly when the case reaches court, are not only how similar are the components of the questioned soils, but also how variable are soils in general in the area under question.
These two factors control the degree of confidence, which can be reached when testing the spatial association between two soils recovered from different locations (in the example above one questioned soil sample recovered from footwear whilst the other from a body deposition site). Soils show considerable but variable degrees of spatial variation. If the recognised spatial variation is not random, and is in fact a function of a number of parameters such as: (a) bedrock geology, (b) superficial geology, (c) soil forming processes, (d) climate, (e) land use, (f) vegetation cover, (g) surface processes and (h) anthropogenic processes, then soil analysis can become a useful predictive or deductive provenancing tool.

In this paper we explore the use of soil data as a predictive tool in the identification of unknown locations based on recovered soil samples. Examples where this is of investigative value are: (a) in the location of clandestine grave sites in missing victim murder enquiries, (b) in the identification of a location where an offence took place (e.g., in rape cases) but also (c) in the determination of places visited by individuals of interest in security-related operations. In addition, understanding the provenance of in particular fine grained soils and sediment has more wide ranging applications in the earth sciences (e.g., Owens et al., 2016).

\section{Predictive Geolocation}

Predictive geolocation can be defined as the use of the physical, chemical and biological attributes of a soil sample in the identification of its provenance. In this sense the "geo" relates to the geographical location rather than the limitation of only using "geo"-logical data in determining the source area. The overall aim of predictive geolocation is to determine the area from which a soil sample was derived. Many aspects of the texture and composition of a soil sample have spatial significance, and the more of these which can be determined, the clearer the geographical profile will be (e.g., Bowen and Craven, 2013). However, such geolocation analysis is not a magic bullet and investigators need to be aware from the outset, that the analysis is in 
most cases unlikely to allow a discrete location to be determined. Instead an environmental profile can be established, which might include the following: (a) the soil types present in the area, (b) the nature of the underlying bedrock geology and any superficial deposits, (c) the nature of chemical and physical processes operating in the area (e.g., chemical vs. physical weathering, surface transport by wind, water, ice etc.), (d) vegetation cover and a description of the overall habitat(s), (e) the geographical ranges of biological species identified in the soil sample, (f) abundance and types of man-made particulate materials and their location significance along with other data in determining the likely human activity and processes in the source area.

Many of these parameters can be overlain using spatial data to refine (i.e., narrow down) and focus the description of the likely source area. As an example, the analysis of a soil sample might lead to the conclusion that the underlying bedrock geology is a Jurassic mudstone, in an area without significant physical remobilisation and dominated by chemical weathering, with a deciduous woodland habitat adjacent to areas of cultivated wheat. The plant species present are consistent with a southern UK geographical range, along with a number of introduced non-native plants. Particulate grains are relatively rare other than minor glass fragments and aggregates coated with asphalt. The overall profile is suggesting a shelter belt of trees bordering a road on one side, with a cultivated field of wheat on the other, on low gradient slopes away from adjacent water courses and underlain by Jurassic mudstone. The soil mineralogy would determine which Jurassic mudstone formation is the likely bedrock geology because of known stratigraphical variations in the bedrock mineralogy. Introduced plants such as Japanese knotweed would be indicative of areas of introduced wastes, potentially indicating proximity to a layby or other areas where a vehicle could be parked at the edge of a road. This very broad example illustrates the type of profile which can be constructed based on a typical soil analysis. This environmental profile can then be used by the investigating officers in conjunction with other strands of evidence (e.g., automatic number plate recognition (ANPR), mobile phone use analysis, eye witness accounts) to focus search assets in potential target areas. It is significant that whilst the derived geographical profile is rather generic it also means that many other locations with different environmental profiles can be excluded as the origin point for the questioned soil. However, once these data are mapped and spatially constrained using the police intelligence, often only one or two areas are consistent with all of the measured required attributes.

\section{Evidence Recovery and Analytical Methods}

Whilst through the work of the IUGS-IFG and other International working groups there is significant progress in the identification of protocols for soil analysis (e.g., Wood et al., 2016), there is no international "standard" analytical approach. Indeed, one could argue that there should not be protocols, but more general guidelines. In some ways this does not matter however, as soils are inherently very variable materials and the best analytical approach needs to be targeted to the specific soil type (and conditions and size of the questioned sample) being examined. In very general terms the major components present in soils are: (a) macroscopic plant fragments, (b) microscopic plant fragments (e.g., pollen, spores), (c) invertebrates and minor components from

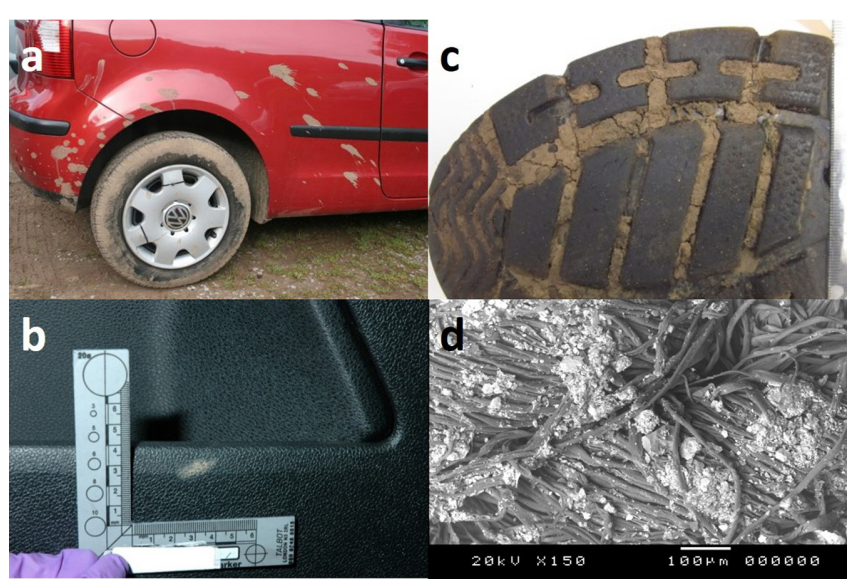

Figure 1. For predictive geolocation analysis, evidence recovery is critical as soil samples representing individual transfer events such as soil splash marks (a), soil smears on vehicle door trims (b), soils within footwear (c) need to be recovered. It is also important that evidence is seen in context so that the mechanism of transfer can be understood - (d) scanning electron microscope image showing soil on denim fabric.

larger animals, (d) rock fragments and mineral grains, (e) neoformed minerals developed during weathering processes, (f) man-made particulate grains and (f) organic residues (Fig. 1). The relative abundance of these different components will vary considerably and as a result the best analytical approach for any individual soil is best determined following an initial visual or low power optical microscopy examination followed by a brief morphological description using standard methods.

\section{Evidence Recovery}

The recovery of environmental trace evidence is best carried out by the investigating scientist rather than during routine examination of exhibits for evidence recovery. This is because not only may the context of the trace evidence on the item being examined have significance itself, but also because it is critical that individual soil depositional events are recovered as separate samples (Pirrie and Ruffell, 2012). The stratigraphy of the soil depositional events is critical - the soil analyst needs to document any sequential events of soil transfer to the item being examined so that they can all be recovered as discrete samples (e.g., Bull et al., 2006). Considering the environmental evidence in the context of the overall exhibit is therefore important (Fig. 1). How many soil types are present?; what are their relative age relationships based on simple rules of superposition?; is there any directionality to the soil transfer to the item? (e.g., was the fabric in direct vertical contact with exposed soils or dragged across a surface (e.g., Murray et al., 2016)) (Fig. 1). Samples of individual depositional events need to be recovered separately although it is possible to analyse different soil transfer events built up as successive layers within for example the tread of a shoe discretely.

Whilst evidence recovery from clothing and footwear is generally very simple, care must be taken with regard to identifying and sampling discrete transfer events. In some cases, washing clothing samples to recover pollen for example has been suggested. However, with this 
approach care needs to be taken with regard to recovering mixed-assemblages, as it has also been argued that some fabric types can trap and retain pollen for considerable periods of time. Thus it is best to recover discrete areas of soil, the matrix of which can then be analysed for pollen as this will predominantly reflect an individual geographical location. The examination of larger items, such as motor vehicles, is more complex, but the same basic principles apply. Bulk sampling (e.g., sweepings of vehicle footwells, scrapings from wheel arches) should be avoided unless the visual examination prior to sampling suggests that the bulk sample does in fact reflect an individual depositional event. The sampling of discrete soil aggregates within mixed samples is a useful approach to obtain single source samples. Whilst data from small discrete samples will relate to individual geographical locations, bulk samples will inevitably represent a mixed assemblage.

Control samples for comparison with unknown (questioned) samples need to be collected in such a way as to mimic the potential forensic event. For example, if during an offence an individual's footwear or clothing will only have come into contact with the exposed ground surface, then it is this surface, which needs to be sampled. The depth of sampling is determined by the nature of the likely ground conditions at the time of the offence - if a surface is dry and firm then only the uppermost surface should be sampled (top few $\mathrm{mm}$ ). In contrast, if the ground conditions are soft then the depth to which footwear would sink into the surface should be sampled. This is because soil composition varies with depth. This becomes more significant if the potential forensic event might have involved digging into the soil profile, as again soil characteristics will vary with depth. In addition, if for example, only the clay fraction (i.e., $<2$ micron fraction) has transferred to, or been retained by, clothing, then the clay fraction of the control soil should be separated and correspondingly analysed.

\section{Analytical Methods}

Because of the huge diversity and complexity of soils, there are many different ways in which they can be analysed (Fig. 2). In general, for predictive geolocation, the more analytical approaches which can be utilised the greater the dataset on which to base the overall interpretation (and in general the greater the narrowing down of likely geographical origin). Analytical methods can be divided into: (a) those which characterise the bulk appearance of the soil such as: (i) visual appearance, (ii) colour, (iii) particle size distribution; (b) methods which determine the composition and texture of the inorganic components including (i) particle texture (microscopy and scanning electron microscopy (SEM)), (ii) soil mineralogy (e.g., optical microscopy, cathodo-luminescence, SEM, automated mineralogy, X-ray diffraction (XRD)), (iii) soil bulk or individual grain geochemistry (e.g., major and trace element geochemistry, electron microprobe grain analysis, laser-ablation-inductively coupled plasma mass spectrometry (LA-ICPMS), transmission electron microscopy (TEM), stable isotope analysis) and (c) methods which determine the composition of the organic components present including: (i) macroscopic identification of plant and animal remains, including DNA analysis, (ii) analysis of microscopic components (e.g., spores, pollen), (iii) organic geochemistry (GC, GC-MS). Man-made components of soils should be captured during many of these analytical stages, but additional methods might also be significant if for pre-

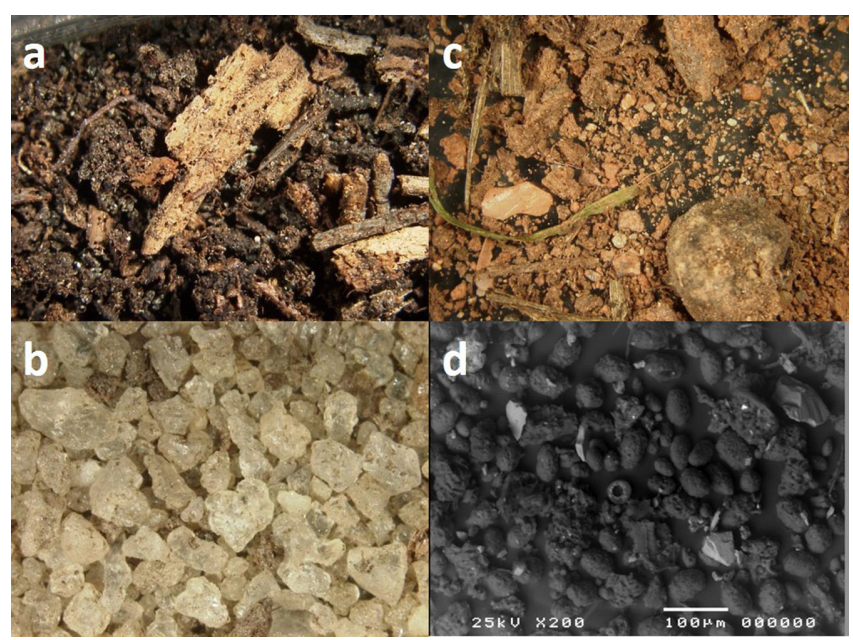

Figure 2. Soils are inherently very variable materials and as such the analytical approach needs to be determined firstly by the visual characterisation of the soils. (a) Humic soil with abundant macroscopic plant debris. (b) Mineral soil composed almost entirely of quartz grains. (c) Mixed soil comprising rock fragments, soil and macroscopic plant debris (grass blade and leaf litter). (a-c) Binocular microscope images, maximum field of view $3 \mathrm{~cm}$. (d) Scanning electron microscope image showing a soil dominated by biogenic material.

liminary examination of the soil suggests the presence of industrial waste materials.

This list of analytical methods is far from exhaustive and in fact there may be additional methods, which would be highly significant in certain soil types and in addressing specific provenance questions, although any method used needs to be scientifically tested and consistency proven. For example, the analysis of reworked microfossils has been significant in several high profile serious criminal cases in the UK (e.g., R. v Huntly). Radiometric dating of individual mineral grains is widely used in traditional sediment provenance studies and has the potential in soil forensics to be very significant in determining different bedrock geology terrains etc. In general, there are four main limiting factors or major challenges to soil forensic analysis: (1) the size of sample available for analysis, (2) the amount of time available in which to carry out the examinations, (3) the funding available for the analysis and (4) the condition of the sample. The ideal scenario for predictive geolocation would be that there is a large sample, collected immediately after the crime was committed, combined with unlimited time and resources, but this is largely not the case in reality. Consequently, the initial visual/binocular/SEM examination and characterization of any soil sample for a predictive geolocation analysis is critical as this can be used to determine the optimum subsequent analytical path for the particular sample. In addition, this determines which analysts are best suited to carry out the examination as no soil scientist/geologist/geomorphologist/palynologist etc. has the breadth of skill set to cover all possible analytical avenues - collaboration between co-workers in forensic soil examination is critical. Although the analytical approach is sample specific there are a range of techniques, which are commonly utilised in predictive geolocation analysis and these are described in more detail below. One of the great advantages of a network such as the IUGS-IFG is that it brings together scientists with complementary expertise, who are readily contactable to provide advice on the best 
approach or method to use in each specific case context.

\section{Bulk Characterisation}

The overall appearance of a soil sample is very significant. Prior to examination, soil samples need to be gently dried in an environment where no cross-contamination will occur. It should be noted (and avoided) if there is any apparent volatile release during drying of the samples. Questioned samples should never be dried in the same environment as the control samples, to avoid any potential cross contamination. Samples are then typically visually examined and photographed and the macroscopic textural features and components described using where possible standard methods: colour, grain size, sorting, rock fragments, mineral grains, macroscopic plant debris, invertebrates or vertebrate debris, man-made materials, fibres, hair, paint, and separated into discrete labelled vials etc. (e.g., Fig. 2). All components should be documented, described and imaged. Visual examination is usually augmented through binocular microscopy.

Following the description of the overall bulk characteristics, representative subsamples can be taken for different analytical pathways. For example if there was a sufficiently large soil sample then subsamples could be prepared for (a) binocular microscopy and SEM analysis, (b) preparation as polished uncovered petrographic thin sections, (c) whole rock or clay fraction XRD, (d) automated SEM-EDS mineral analysis, (e) elemental analysis, and (f) organic analysis and palynological preparation etc. In addition, any man-made particulates present (e.g., plastics, fibres) can also be recovered as separate subsamples/ productions for examination by forensic staff in the appropriate disciplines. Samples should not be sieved into multiple size fractions as there is no analytical requirement to do so. Larger rock fragments or man-made materials (e.g., brick, concrete etc.) can be handpicked from the bulk sample at this stage for preparation for optical examination or more detailed laboratory analyses (e.g., SEM, XRD).

\section{Grain Scale Textural Features}

Following the description of the overall bulk sample characteristics, further grain specific features can be documented. This can be achieved through binocular microscopy (and petrography if available) along with scanning electron microscopy (SEM) (Fig. 3). Low vacuum SEM allows samples to be examined without the need for

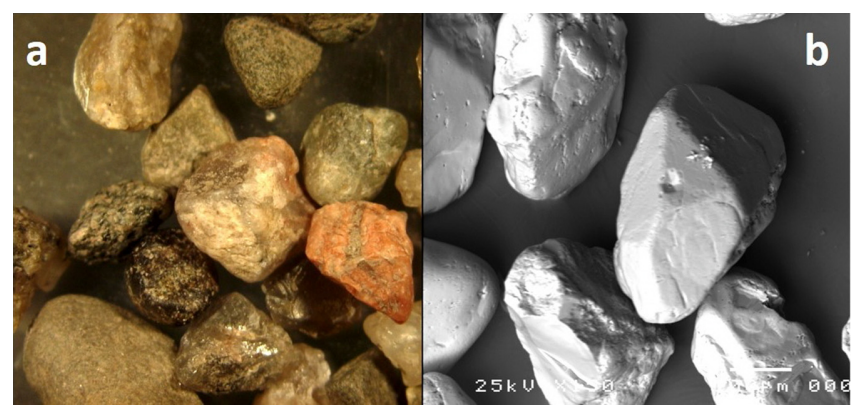

Figure 3. Surface textural analysis through (a) binocular microscopy and (b) scanning electron microscopy allows surface processes to be inferred. coating prior to imaging. Grain specific features typically include textural analysis such as particle shape, surface texture, surface coatings. For example, grain size, shape and surface texture can all relate to surface processes operating in the environment(s) where the soil was derived (e.g., quartz grain textural analysis - Bull and Morgan, 2006). In addition, grain textural features (e.g., the presence of quartz overgrowth cements on detrital quartz grains) can also provide provenance specific information about the grains. Many macroscopic biogenic components such as plant debris, invertebrates and fragments of vertebrates can be more adequately documented through binocular microscopy and SEM analysis, as can a wide diversity of man-made particulate grains.

\section{Soil Mineralogy}

There are a range of methods available to determine the mineralogy of both the "bulk" soil sample, any larger rock fragments present within the sample and different fractions (e.g., clays). If the sample is large enough and there are sufficient sand-grade or coarser particles then the starting point for analysis can be based around traditional optical transmitted light microscopy of uncovered polished thin sections (see Bowen and Caven, 2013). Thin sections in this case are usually effectively grain mounts (Fig. 4); very few forensic soil samples would be large enough to be prepared as "soil" thin sections as is carried out in soil science "micromorphology" studies. Thin sections of grain mounts do however, allow the soil mineralogical data to be seen in textural context. Preparation of the samples as uncovered sections means that the same sample can then be used for other analytical methods including cathode-luminescence, manual SEM-EDS analysis, auto-

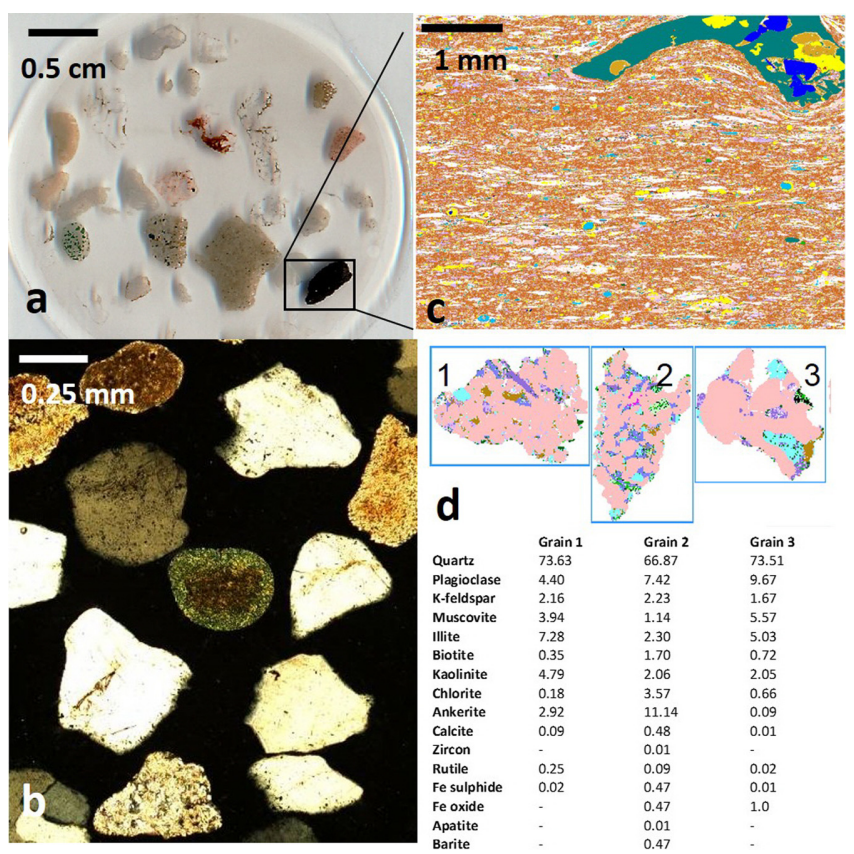

Figure 4. Techniques to determine soil mineralogy in textural context. (a) Binocular microscopy of large rock fragments. (b) Optical microscopy of sand grade sample. (c) Automated mineralogy image of a fragment of mudstone. Each colour relates to a different composition mineral. (d) Example of automated mineral data for three small rock fragments where the modal mineralogy is reported for each individual rock fragment so that the data are in textural context. 
mated SEM-EDS analysis, electron microprobe analysis, LA-ICP-MS etc.

Automated mineral analysis using a range of now widely available SEM-EDS analytical systems is a means of quantitatively analysing the soil mineralogy but retaining the textural associations between the different minerals (e.g., Pirrie et al., 2013, 2014) (Fig. 4). The advantage of automated mineral analysis is that sample measurement is operator independent and very large numbers of individual mineral grains can be analysed based on the acquisition of many thousands of EDS analysis points. The limitation to this approach is that minerals with very similar, or the same chemistry, but different crystal systems, cannot be distinguished (the same limitation applies to any SEM-EDS based mineral analysis). XRD analysis can complement automated mineral analysis in particular in differentiating between different mineral phases of very similar chemistry (or indeed mineral polymorphs) and in the analysis of different clay mineral species. However, routine powder XRD lacks specific textural spatial information and thus context.

\section{Bulk and Single Grain Geochemistry}

Whilst analysis of the bulk soil geochemistry is possible, this methodology rarely provides useful provenance information, and sample size and representivity are significant issues, although Lark and Rawlins (2008) present a study showing that soil provenance based on geochemical data can be achieved. There are rare cases where analysis of the bulk soil chemistry may be appropriate, in for example areas where there is significant contamination of near surface environments as a result of past historical mining activity. For example in Cornwall and Devon in SW England, historical mining activity released significant volumes of mine wastes into the environment. Different river catchments draining into the coastal estuary systems drained different areas of mineralisation and mineral processing and as such the sediments in each estuary, and indeed within individual tributaries are geochemically distinctive. Hence in this area, the bulk geochemistry of an estuarine mud sample could be used to determine which estuary/tributary it was sourced from, but this degree of geochemical distinctiveness is not that common. Again, analysis is in this case is not in textural or mineralogical context, which is significant in terms of provenance determination.

In contrast the use of a range of analytical methods to determine individual grain chemistry can provide provenance specific data, in exactly the same way as varietal heavy mineral analysis is widely used in both pedological (e.g., Fitzpatrick et al., 2002) and sediment provenance studies (Fig. 5). The individual grain chemistry of both heavy minerals and also mineral species not typically encountered as major constituents in soils can be determined, and although commonly making up a small fraction of the overall sample, can be provenance specific (e.g., Bong et al., 2012). Grains for geochemical characterisation can be located during optical, SEM or automated mineral analysis and then quantified. The wide range of other methods commonly adopted in sediment provenance studies can equally well be applied to the analysis of soil samples. For example the application of single grain radiometric dating would be a valuable tool in determining different geological provenances in areas where the overall bulk mineralogy may be very similar.

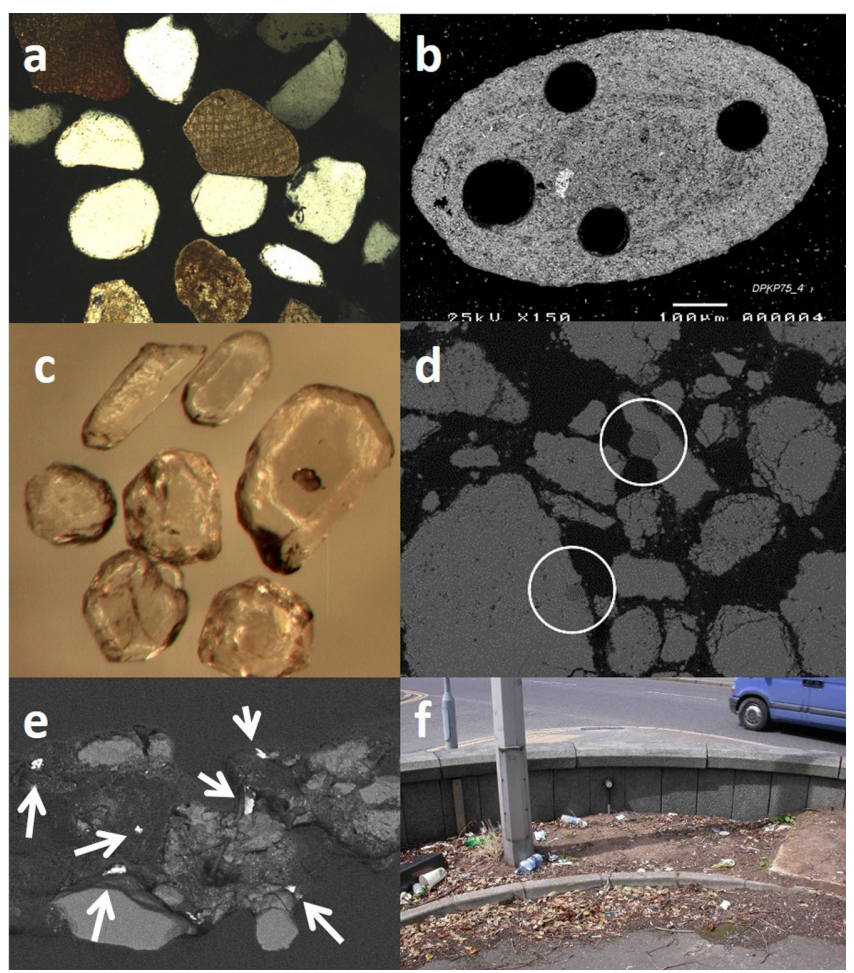

Figure 5. Examples of additional analytical techniques and man-made materials. (a) Bioclasts (microfossils) can provide valuable provenance information. (b) Carbonate ooid grain originally derived from a Jurassic limestone showing the position of laser ablation pits for grain chemistry. (c) Heavy minerals, such as zircon grains, could be used for grain dating (image courtesy of Dr. Ian Millar, BGS). (d) Fragments of limestone with characteristic textures due to crushing to produce an agricultural "lime" product. The circled mineral grains are tridymite, which allowed the source quarry to be determined. (e) Scanning electron microscope image of particles recovered from a victim's hair. The bright particles (arrowed) are from a copper grease product. (f) An example of an urban environment in West Belfast with man-made particulate debris mixed with soil (image courtesy of Dr. Alastair Ruffell, Queens).

\section{Micropalaeontology}

During either the examination of the bulk characteristics of a soil sample or during thin section analysis, the presence of either microfossils reworked from their original geological hosts, or still retained within small rock fragments may be recognised (Fig. 5). Microfossils need to be distinguished from extant micro-organisms either living or dead within the soil sample. If microfossils are present then they can be highly provenance specific and as such merit as full an identification as possible by relevant subject specialists. Potential alternative sources of microfossils also need to be considered. This was discussed by Rawlins et al. (2006) in a study where Carboniferous spores were originally derived from samples of domestic coal rather than a Carboniferous bedrock source. Micropalaeontological data can help determine the age of underlying bedrock units and can in some cases provide very specific stratigraphical and potentially spatial provenance data. 


\section{Man-made Particulates}

The abundance and types of man-made particulate grains in soil samples is highly variable but can be very useful in determining the nature of the surface environment the soil sample was derived from. Man-made grains are present in most soils, and are abundant in urban and semi-urban settings and along major transport routes (Fig. 5). Not only can such grain types help determine whether a soil is from an urban or rural setting, but grain analysis can also help determine the nature of the urban environment and the types of any industrial processes operating in that environment. For example man-made grains might include construction materials (e.g., bricks, concrete, roofing materials, plasters and renders, paint flakes), which help determine the nature of the local built environment. Other particle types might indicate the nature of industrial processes operating and discharging wastes into the environment. Particulate contamination in soils may be "historical" rather than modern and may relate to earlier periods of industrial activity preserved as "fossils" within the soil profile. In some cases, grains may show evidence of alteration or degradation as a result of being present in the near surface environment for considerable periods of time. The significance, or other-wise, of any man-made particulate grains requires the analyst to have a wide ranging knowledge of the use of such materials.

\section{Biogenic Components}

The analytical methods to determine the biogenic components present in soils will be controlled by the condition of the sample and the types of materials present. Macroscopic materials can be identified using a combination of optical and SEM microscopy, along with more advanced methods such as the use of plant or animal DNA analysis. Bulk sub-samples can be prepared using standard palynological preparation methods to determine the pollen, spores and other organic walled micro-organisms present (e.g., Brown, 2006). Again care needs to be taken to differentiate between extant taxa and sub-fossil taxa within a sample. The organic compounds present can be analysed (e.g., Dawson and Mayes, 2014) to provide information on likely plant species at the questioned location and on habitat conditions. Overall the biogeographical ranges of all of the taxa and their biology need to be considered together to see if they represent: (a) a coherent ecological community and (b) a single geographically consistent assemblage. Outliers need to be taken in context, as in a UK forensic soil investigation in which the presence of snake skin of a particular taxa originated from an individual exotic pet rather than indicating a rather unusual biogeographical range.

\section{Data Interpretation and Provenancing}

The overall aim of the combination of the many layers of analysis is to determine the geographical origin, or provenance, of an unknown soil. In reality, commonly the work will result in the provision of an overall geographical profile comprising the likely soil type, underlying geological bedrock, the nature of the near surface environment in terms of physical and chemical processes, proximity to and type of human processes, the biogeography in terms of vegetation assemblages and the biogeographical ranges of taxa.

To assist data interpretation, the results need to be compared with available and suitable spatial databases. Databases of value might include soil surveys and maps, plant/animal distribution data, geological maps etc. In many parts of the world there is a strong bedrock geology control on soil mineralogy/compositon. In areas where intense chemical weathering over very extended periods of time has occurred, this relationship may be less easy to determine. Clearly there needs to be an understanding of weathering processes in terms of neoformed minerals within the soil profile and their likely precursor minerals. In fact the soil composition can be used to indicate the types and intensity of weathering processes and as such can be a useful provenance indicator. The only areas where the linkage between bedrock geology and soil mineralogy might hold less true are areas where there are very thick sequences of superficial, especially glacial, sediments overlying the bedrock geology. In this case, soil mineralogy may be strongly influenced by the mineralogy of the superficial deposits. Either way, the mineralogy of an unknown soil is generally a good predictor for the underlying bedrock geology, and as such widely available bedrock and superficial geology maps can be used to interpret potential source areas.

Textural analysis of both the bulk sample and on a grain by grain basis provide data on the surface processes operating in the environment and as such assist in the construction of an overall environmental profile. Grain size, shape, sorting, surface textures of grains link with surface processes. For example, it is well known that quartz grain surface texture can be used to indicate the processes of particle transport (e.g., Bull and Morgan, 2006). Textural data can be compared with both superficial geological maps, but also with soil survey datasets.

The biological attributes can provide three main strands of information: (1) are discrete ecological assemblages present indicative of a single location?, (2) what is the nature of the surface vegetation within the area the soil is derived from? and (3) what are the known biogeographical ranges of the taxa present? Care needs to be taken in such interpretation in terms of the possibility of introduced plants and taxa being present, which are outside of their natural biogeographical ranges. However, the possibility of anthropogenic transfer also pertains to inorganic components. Often such biological aspects of the soil information can help exclude areas where the samples could not naturally have originated (see the article by Dawson in this volume for further details).

Analysis of the types and abundance of man-made particulate grains can be used to further describe the near surface environment in terms of human land use. In terms of provenancing, the spatial distribution of man-made wastes is probably one of the least well documented aspects of soil characteristics. In the UK even in rural settings, man-made particulate grains are commonly present, however, the UK has a small surface area, a large population and a long history of human occupation and land use. In areas which are less densely populated and with a shorter history of intense land use, man-made particles may be less abundant, although in general, in developing areas the management of waste streams is less highly regulated than in developed countries, hence near surface contamination can be more common. The detailed analysis of man-made particulates can however, provide additional layers of information such as the types of human activity within the area the soil has been derived from.

With the increasing application of spatial datasets through GIS 
applications (see article by McKinley in this volume) the many layers of data collected above can best be viewed through a similar approach. In addition in an investigation the predictive geolocation data can be overlain with other evidential/intelligence datasets regarding the movement of individuals of interest to an enquiry. The environmental profile will not only allow areas of significant interest to be identified but it will also allow very many areas to be excluded as the potential source for the questioned soil sample allowing the targeting of search assets. Additional research into the spatial characteristics of soils and other near surface materials will improve the ability of predictive geolocation as a tool in forensic investigations.

\section{Acknowledgements}

We are grateful to Laurance Donnelly and colleagues within IUGSIFG for the opportunity to include this paper. We are also very grateful to all of our colleagues in the forensic geoscience community for discussion. Aspects of this paper are based on forensic casework experience, which cannot be directly attributed but we are grateful to our colleagues in the forensic and policing communities for the opportunity to work on a wide range of investigations. We are grateful to Allan Pidduck for comments on the draft manuscript and Rob Fitzpatrick for a thorough review of the paper.

\section{References}

Bong, W.S.K., Nakai, I., Furuya, S., Suzuki, H., Abe, Y., Osaka, K., Matsumoto, T., Itou, M., Imai, N., and Ninomiya, T., 2012, Development of heavy mineral and heavy element database of soil sediments in Japan using synchrotron radiation X-ray powder diffraction and highenergy $(116 \mathrm{keV}) \mathrm{X}$-ray fluorescence analysis 1 . Case study of Kofu and Chiba region: Forensic Science International, v. 220, pp. 33-49.

Bowen, A.M., and Craven, E.A., 2013, Forensic provenance investigations of soil and sediment samples. in Pirrie, D., Ruffell, A., and Dawson, L.A. (eds.), Environmental and criminal geoforensics: Geological Society of London, Special Publication, v. 384, pp. 9-25.

Brown, A.G., 2006, The use of forensic botany and geology in war crimes investigations in NE Bosnia: Forensic Science International, v. 163, pp. 204-210.

Bull, P.A., and Morgan, R.M., 2006, Sediment fingerprints: a forensic technique using quartz sand grains: Science and Justice, v. 46, pp. 107-124.

Bull, P.A., Parker, A., and Morgan, R.M., 2006, The forensic analysis of soils and sediment taken from the cast of a footprint: Forensic Science International, v. 162, pp. 6-12.

Dawson, L.A., and Mayes, R.W., 2014, Criminal and environmental soil forensics: soil as physical evidence in forensic investigations. in Murphy, B.L., and Morrison, R.D. (eds.), Introduction to environmental forensics ( $3^{\text {rd }}$ edition): Academic Press, Oxford, pp. 457-486.

Fitzpatrick, R.W., and D.J. Chittleborough, D.J., 2002, Titanium and zirconium minerals. in Dixon, J.B., and Schulze, D.G. (eds.), Soil mineralogy with environmental applications: Soil Science Society America, Book Series No. 7, Madison, pp. 667-690.

Lark, R.M., and Rawlins, B.G., 2008, Can we predict the provenance of a soil sample for forensic purposes by reference to a spatial database?: European Journal of Soil Science, v. 59, pp. 100-1006.

Murray, K.R., Fitzpatrick, R.W., Bottrill, R.S., Berry, R., and Kobus, H., 2016, Soil transference patterns on bras: Image processing and laboratory dragging experiments: Forensic Science International, v. 258, pp. $88-100$.
Owens, P.N., Blake, W.H., Gaspar, L., Gateuille, D., Koiter, A.J., Lobb, D.A., Petticrew, Reiffarth, D.G., Smith, H.G., and Woodward, J.C., 2016, Fingerprinting and tracing the source of soils and sediments: Earth and ocean science, geoarchaeological, forensic and human health implications: Earth Science Reviews, v. 162, pp. 1-23.

Pirrie, D., and Ruffell, A., 2012, Soils and geological trace evidence. in Marquez Grant, N., and Roberts, J. (eds.), Forensic ecology handbook: Blackwell-Wiley.

Pirrie, D., Rollinson, G.K., Power, M.R., and Webb, J., 2013, Automated forensic soil mineral analysis; testing the potential of lithotyping. in Pirrie, D., Ruffell, A., and Dawson, L.A. (eds.), Environmental and criminal geoforensics: Geological Society of London, Special Publication, v. 384, pp. 47-64.

Pirrie, D., Rollinson, G.K., Andersen, J.A., Wootton, D., and Moorhead, S., 2014, Soil forensics as a tool to test reported artefact find sites: Journal of Archaeological Science, v. 41, pp. 461-473.

Rawlins, B., Kemp, S.J., Hodgkinson, E.H., Riding, J.B., Vane, C.H., Poulton, C., and Freeborough, K., 2006, Potential and pitfalls in establishing the provenance of Earth-related samples in forensic investigations: Journal of Forensic Science, v. 51, pp. 832-845.

Ritz, K., Dawson, L., and Miller, D., 2009, Criminal and environmental soil forensics: Springer, Berlin, $519 \mathrm{p}$.

Woods, B., Lennard, C., Kirkbride, K.P., and Robertson, J., 2016, Soil examination for a forensic trace evidence laboratory - Part 3: A proposed protocol for the effective triage and management of soil: Forensic Science International, v. 262, pp. 46-55.

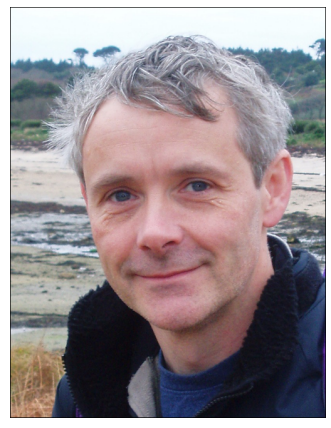

Duncan Pirrie, BSc (Hons), $\mathrm{PhD}$, is a geologist with over 30 years experience in the analysis of materials. A background in field geology laid the foundations for a move across into more analytical aspects of geology. Much of his research has revolved around the understanding of provenance of geological materials. He pioneered several application areas for automated mineral analysis based on SEM-EDS including its use in forensic geology. He has worked on trace evidence analysis in over 100 serious crime investigations in the UK and overseas.

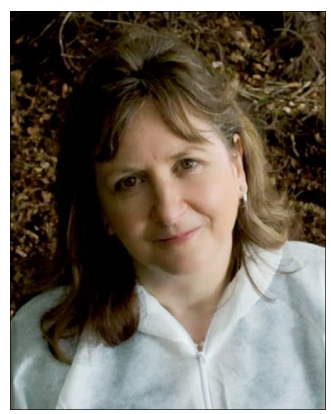

Lorna Dawson, BSc (Hons), $\mathrm{PhD}$, is Head of Forensic Soil Science at the James Hutton Institute, visiting Professor at Robert Gordon University, a Chartered Scientist a Fellow of the Institute of British Soil Scientists and a Fellow of the Royal Society of Arts. She has worked on over 100 cases with police forces and agencies across the UK and overseas, in soil trace evidence and search. She is a member of the National Crime Agency, holds diplomas in civil and criminal law $(2011,2012)$ and regularly attends court as an expert witness. She sits on the British Association of Science General Committee, holds a diploma in Science Communication (2010).

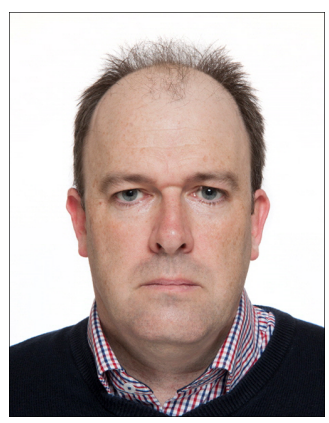

Giles Graham has a degree and $\mathrm{PhD}$ in chemistry and geology. Since 2007, he has worked at the Atomic Weapons Establishment on research topics relating to nuclear forensic science. Prior to this Giles was a Post-Doctoral Researcher and then Staff Member at Lawrence Livermore National Laboratory in the United States where he worked on a number of different projects including the analysis of cometary dust returned to Earth by the NASA Stardust Sample Return Mission. Giles is a Professional Member of the Chartered Society of Forensic Sciences and Fellow of the Royal Microscopical Society. 